\title{
Avaliação das propriedades mecânicas de compósitos de matriz cimentícia com microcelulose cristalina
}

\author{
Evaluation of mechanical properties of cement \\ compounds with microcrystalline cellulose
}

\author{
Katherine Kaneda Moraes ${ }^{1}$, Romel Dias Vanderlei ${ }^{1}$, \\ Vinícius Carrijo dos Santos ${ }^{1}$, João Paulo Zampieri ${ }^{1}$, Luana Capelin ${ }^{1}$
}

\footnotetext{
${ }^{1}$ Departamento de Engenharia Civil, Universidade Estadual de Maringá, Maringá, PR, Brasil. e-mail:katherinekaneda@hotmail.com; rdvanderlei@uem.br; vinicius.gc@ hotmail.com; joaopaulozamp2940@gmail.com; luanah.capelin@ @otmail.com
}

\begin{abstract}
RESUMO
A adição de micropartículas em materiais cimentícios é um método que vem sendo investigado nas últimas décadas, apresentando a possibilidade de melhorar o desempenho mecânico destes materiais. Este estudo tem como objetivo avaliar a influência causada pela adição de uma micropartícula, a microcelulose cristalina (MCC), nas propriedades mecânicas de argamassas cimentícias. Esta avaliação se deu por meio da utilização de diferentes dosagens de MCC, em relação à massa de cimento, e um fator a ser destacado é a busca pela manutenção da trabalhabilidade da argamassa cimentícia, por meio do ajuste em sua relação água/cimento. Foram realizados ensaios de determinação de índice de consistência, resistência à compressão, resistência à tração na flexão, ensaios de absorção e também a captura de imagens das argamassas por meio da Microscopia Eletrônica de Varredura (MEV). De acordo com os resultados dos ensaios, constatou-se que, entre as dosagens de MCC analisadas, as argamassas com adição de 0,2\% de MCC, em relação à massa de cimento, apresentaram os melhores desempenhos mecânicos, quando comparados ao desempenho das argamassas de referência. Os incrementos de resistência à compressão alcançados foram de: $4 \%$ aos 3 dias de idade, $9 \%$ aos 7 dias e $2 \%$ aos 28 e 56 dias. Houve um acréscimo de $6 \%$ na resistência à tração na flexão das argamassas aos 28 dias de idade. Já os resultados dos ensaios de absorção, demonstraram que as argamassas com adição de $0,2 \%$ de MCC, em relação à massa de cimento, foram as que apresentaram um menor índice de absorção de água e menor índice de vazios. Por meio do MEV pôde-se identificar a MCC no interior da matriz cimentícia e verificar a maneira como a mesma se encontra disposta no interior do material.
\end{abstract}

Palavras-chave: MCC, resistência à compressão, resistência à tração na flexão, absorção, MEV.

\begin{abstract}
The addition of microparticles in cementitious materials is a method that has been investigated in recent decades, presenting the possibility of improving the mechanical performance of these materials. The goal of this study is to evaluate the influence of the addition of a microparticle, microcrystalline cellulose (MCC), on the mechanical properties of cementitious mortars. This evaluation was carried out using different dosages of MCC in relation to the cement mass, and a point to be considered is the search for the maintenance of the workability of the cement mortar, through the adjustment of its water/cement ratio (w/c). Tests were performed to determine consistency index, compressive strength, flexural tensile strength, absorption tests and the image capture of the mortars by Scanning Electron Microscopy (SEM). According to the results of the tests, it was found that, among the analyzed MCC dosages, mortar with $0,2 \%$ of MCC, in relation to the cement mass, presented the best mechanical performance, when compared to performance reference mortars. The increments of compressive strength reached were: $4 \%$ at 3 days of age, $9 \%$ at 7 days and $2 \%$ at 28 and 56 days. There was a $6 \%$ increase in the flexural tensile strength of the mortars at 28 days of age. The results of the absorption tests showed that mortars with $0,2 \%$ of MCC in relation to the cement mass were those with a lower water absorption index and lower voids index. Through SEM, it was possible to identify the MCC within the cementitious material and to verify the way it is disposed inside the material.
\end{abstract}


Keywords: MCC, compressive strength, flexural tensile strength, absorption, SEM.

\section{INTRODUÇÃO}

Liderando o ranking dos materiais de construção mais utilizados pelo homem, o concreto, composto por materiais aglomerantes, água e agregados graúdo e miúdo, vem recebendo grande atenção de pesquisadores e indústrias do ramo. Por se tratar de um material largamente utilizado em todo o mundo, o investimento no desenvolvimento de sua tecnologia é de fundamental importância. Atualmente, vários novos tipos de concreto estão sendo desenvolvidos, alguns já se encontram no mercado e outros encontram-se em fase de estudo e testes laboratoriais. Dentre eles destacam-se o concreto reforçado com fibras, o concreto autoadensável, concreto de pós reativos, concretos com a incorporação de nanopartículas, entre outros.

Este estudo faz uma abordagem da argamassa cimentícia, composta pelos mesmos materiais que constituem o concreto, com exceção do agregado graúdo, ou seja, a argamassa, conforme MEHTA E MONTEIRO [1], consiste em uma mistura de areia, cimento e água, como se fosse um concreto sem o agregado graúdo. No contexto dos novos materiais cimentícios que vem sendo desenvolvidos, esta pesquisa apresenta o enfoque na argamassa cimentícia com a adição de micropartículas, neste caso a micropartícula utilizada é a Microcelulose Cristalina (MCC).

A MCC é obtida a partir da celulose natural e possui vasta aplicação em vários setores da indústria. Suas aplicações podem ser encontradas nas indústrias em geral, porém, a MCC encontra-se consolidada principalmente em aplicações nas indústrias alimentícia, farmacêutica e cosmética. A MCC é produzida hidrolisando as cadeias de celulose, sendo extraída de matéria vegetal por meio de um ácido mineral que é diluído à sua temperatura de ebulição. Desta forma, o processo de hidrólise remove a maior parte da fração amorfa e destrói a morfologia fibrilar da celulose, produzindo a MCC (HOYOS et al. [2]).

O concreto, assim como a argamassa cimentícia, apresenta uma estrutura heterogênea e complexa. De acordo com DUART [3] a fase sólida do concreto endurecido é composta por agregados, hidratos e grãos de clínquer anidros, já a fase porosa contém vazios preenchidos com água ou ar, estes apresentam uma forma muito complexa e os materiais cimentícios têm sua microestrutura modificada durante o processo de hidratação ao longo do tempo, o que acaba por afetar suas propriedades. Assim, a utilização de materiais em nano e microescala permitem o preenchimento dos vazios presentes na fase porosa do concreto, de forma que o índice de vazios tende a diminuir e, por consequência pode haver uma melhoria em suas propriedades mecânicas.

Ao se atribuir ao concreto melhores propriedades mecânicas e de durabilidade, é possível tornar as construções mais eficientes, logo estas poderão contar com uma vida útil mais longa, reduzindo a necessidade de demolições e por consequência de extração de recursos naturais para abastecer a indústria da construção. Atualmente, existe uma crescente preocupação com a escassez dos recursos naturais não renováveis, estes que são muito empregados na indústria da construção civil e nos canteiros de obras. A opção de utilizar materiais provenientes de fontes renováveis e sustentáveis na construção civil, consiste numa prática benéfica tanto para o meio ambiente quanto para o referido setor.

Partindo do pressuposto de que a MCC, por se tratar de uma partícula na microescala, tem o potencial de atuar na microestrutura interna do concreto, preenchendo os vazios existentes, espera-se com este estudo, verificar quais são os efeitos quando de sua incorporação em argamassas, avaliando suas propriedades mecânicas.

As pesquisas voltadas ao estudo da nano e microcelulose em materiais cimentícios são relativamente recentes e têm demonstrado resultados satisfatórios. Em estudo realizado por CAO et al. [4] investigou-se a influência da adição de nanocelulose cristalina (NCC) sobre o desempenho da pasta de cimento, sendo possível verificar um aumento de $30 \%$ na resistência à flexão, com a inserção de uma taxa de $0,2 \%$ de nanocelulose em relação ao cimento. SILVA [5] analisou o efeito da adição de MCC em argamassas de cimento. Os resultados do estudo demonstraram um aumento da resistência à compressão em cerca de $30 \%$, nas idades entre 7 e 28 dias, com uma taxa de $0,2 \%$ de MCC em relação ao cimento. Além disso, pôde-se alcançar também um significativo aumento na resistência à flexão, atingindo o valor de $7,67 \mathrm{MPa}$, a uma taxa de $0,6 \%$ de MCC em relação ao cimento.

Quando se trata da utilização de materiais em micro e nano escala em matrizes cimentícias, uma considerável atenção deve ser dispensada ao processo a dispersão destes. De acordo com PARVEEN et al. [6], assim como em outros materiais nano e micro, a dispersão da MCC é altamente importante, no que se diz respeito às propriedades mecânicas, tendo em vista que a aglomeração de MCC pode reduzir significativamente a sua eficiência de reforço e provocar defeitos nos materiais cimentícios.

Outro ponto importante que se deve considerar é que a MCC apresenta a característica de absorver 
água do meio em que está inserida. De acordo com HOYOS et al. [2], os microcristais pertencentes às microfibrilas da celulose são altamente hidrofílicos, ou seja, possuem alta capacidade de retenção de água. Esta característica da MCC pode comprometer a trabalhabilidade do material cimentício, no caso de reter a água utilizada na etapa de dosagem para sua hidratação. Para MEHTA E MONTEIRO [1], a trabalhabilidade do concreto fresco pode afetar diretamente na capacidade de bombeamento e na construtibilidade, graças ao fato de que esta propriedade determina a facilidade com que uma mistura de concreto pode ser manipulada de maneira que não haja segregação prejudicial.

O presente trabalho contempla a manutenção da trabalhabilidade do material cimentício por meio da alteração na relação água/cimento $(\mathrm{a} / \mathrm{c})$ que compõe as argamassas, levando em consideração o comportamento que a MCC apresenta retenção de água. Desta forma, as propriedades mecânicas do material foram influenciadas pela adição de diferentes teores de $\mathrm{MCC}(0,2 \%, 0,4 \%, 0,6 \%, 0,8 \%$ e $1 \%$, em relação à massa de cimento) e também pelo aumento na relação água/cimento utilizada para o preparo das argamassas, à medida em que os teores de MCC forem aumentando. As propriedades avaliadas foram a resistência à compressão, resistência à tração na flexão, absorção de água e para a caracterização morfológica das argamassas foram capturadas imagens por meio do Microscópio Eletrônico de Varredura (MEV).

\section{MATERIAIS E MÉTODOS}

Com relação ao programa experimental, este foi dividido em 5 fases, sendo elas:

I $\quad$ Caracterização dos materiais -Fase 1;

II Preparo da solução de MCC - Fase 2;

III Determinação da relação a/c por meio da fixação do índice de consistência- Fase 3;

IV Ensaios com a argamassa em estado endurecido - Fase 4;

V Captura de imagens por meio do Microscópio Eletrônico de Varredura (MEV) - Fase 5.

Cada fase será descrita nos tópicos apresentados na sequência.

\subsection{Materiais}

Os materiais utilizados neste estudo foram o cimento, a areia, água e a Microcelulose Cristalina (MCC).

O material aglomerante utilizado para a composição da argamassa cimentícia foi o cimento Portland de alta resistência inicial - CPV - ARI, fornecido pela INTERCEMENT BRASIL [7]. De acordo com a ABNT NBR 5733 [8], o Cimento Portland de alta resistência inicial consiste em um aglomerante hidráulico, o qual atende às exigências de alta resistência inicial e é obtido por meio da moagem de clínquer Portland, e é constituído, em sua maior parte, de silicatos de cálcio hidráulicos, ao qual se adiciona, durante a operação, a quantidade necessária de uma ou mais formas de sulfato de cálcio.

Foi utilizada a areia normal brasileira, padronizada conforme a ABNT NBR 7214 [9], fornecida pelo Instituto de Pesquisas Tecnológicas - IPT, em quatro frações granulométricas, grossa, média grossa, média fina e fina. As quantidades de cada fração granulométrica de areia normal utilizadas para cada traço 1:3, são determinadas pela ABNT NBR 7215 [10].

A água utilizada no estudo foi a da rede pública de abastecimento (SANEPAR), do município de Maringá/Paraná.

A Microcelulose Cristalina utilizada nos ensaios foi fornecida pelo Laboratório SIGMA - ALDRICH CORPORATION [11]. O material consiste em uma MCC em pó, extraída do algodão, com coloração branca. Os resultados da caracterização da MCC utilizada no estudo são apresentados na Tabela 1 e foram fornecidas pelo fabricante.

Tabela 1: Caracterização da MCC.

\begin{tabular}{l|l}
\hline \multicolumn{2}{c}{ MICROCELULOSE CRISTALINA - MCC } \\
LABORATÓRIO: SIGMA ALDRICH CORPORATION \\
\hline Análise & Especificação \\
\hline Aparência (cor) & Branca ou praticamente branca \\
\hline Aparência (forma) & Pó \\
\hline Resíduo na ignição & $\leq 0,1 \%$ \\
\hline Metais pesados & $\leq 0,001 \%$ \\
\hline
\end{tabular}




\begin{tabular}{l|l}
\hline $\mathrm{Ph}$ & $4,5-7,5$ \\
\hline Densidade $(\mathrm{g} / \mathrm{ml})$ & 0,6 \\
\hline Tamanho da partícula $(+60$ mesh) & $\leq 10 \%$ \\
\hline Tamanho da partícula $(+200$ mesh) & $\geq 40 \%$ \\
\hline Perda na secagem & $\leq 7 \%$ \\
\hline Tamanho da partícula & $51 \mu \mathrm{m}$ \\
\hline Cheiro & Inodora \\
\hline
\end{tabular}

\subsection{Preparo da solução da MCC para inserção nas argamassas}

Antes de ser inserida nos traços de argamassa, foi necessário que a MCC passasse por uma etapa de preparação. A fase de preparação se iniciou pela pesagem das taxas de $0,2 \%, 0,4 \%, 0,6 \%, 0,8 \%$ e $1 \%$, em relação à massa de cimento. Na sequência, cada uma das quantidades referentes as porcentagens apresentadas foram colocadas em becker com $225 \mathrm{ml}$ de água, onde permaneceram por 48 horas, para que estas absorvessem o máximo de água, atingindo assim o maior grau de saturação. Assim, cada uma das amostras foi levada a um agitador magnético, onde permaneceram agitando durante 45 minutos, para garantir sua dispersão na água, e após este tempo a solução de MCC era adicionada imediatamente a argamassa para não comprometer o processo de dispersão. Esta metodologia de dispersão foi adaptada de PARVEEN et al. [12]. A Figura 1 ilustra o procedimento de preparo da solução de MCC antes de sua adição na argamassa.

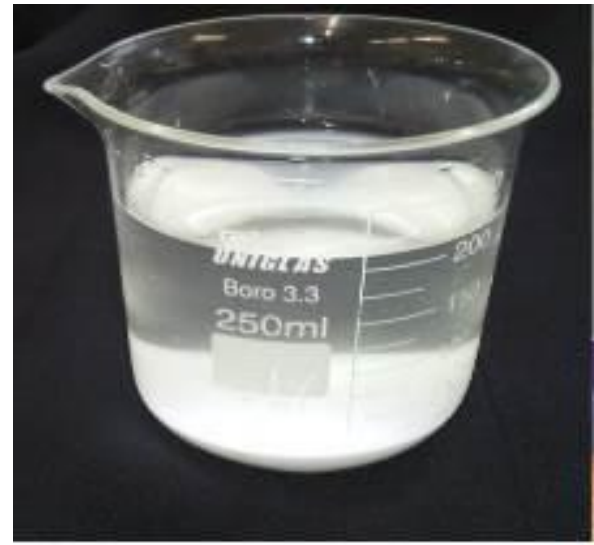

(a)

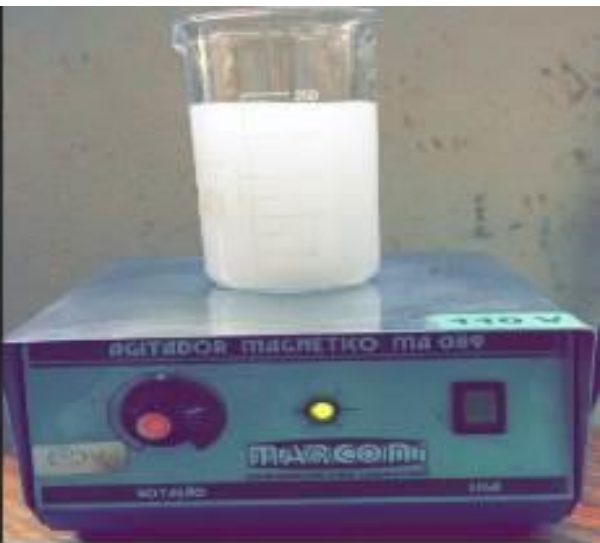

(b)

Figura 1: Procedimento de preparo da solução de MCC: (a) MCC em solução de $225 \mathrm{ml}$ de água; (b) MCC durante processo de agitação em agitador magnético.

A etapa de preparo da solução de MCC para inserção na argamassa é um dos pontos-chave no estudo de materiais cimentícios com adição de nano e micropartículas, uma vez que o misturador convencional de argamassa pode não garantir a adequada dispersão destas partículas ao longo de toda a matriz cimentícia, resultando na aglomeração das mesmas em determinados pontos da matriz. Ou seja, as melhorias que podem ser proporcionadas às propriedades das argamassas estão condicionadas a uma boa dispersão das partículas adicionadas.

\subsection{Determinação da relação a/c por meio da fixação do índice de consistência}

Para a determinação da relação a/c das argamassas, primeiramente foi realizado o preparo do traço de argamassa e, na sequência realizava-se o ensaio de determinação do índice de consistência, cujo resultado deveria ser igual a $180 \pm 10 \mathrm{~mm}$, sendo este o espalhamento considerado neste estudo como ideal para a manutenção das condições de trabalhabilidade do material. Os traços de argamassa foram preparados com $0 \%, 0,2 \%$, 0,4\%, 0,6\%, 0,8\% e 1\% de MCC e, a quantidade necessária de água para manter fixo o índice de consistência teve de ser determinada experimentalmente para cada argamassa pois, à medida em que se aumenta a porcentagem de MCC, o índice de consistência das argamassas tende a diminuir. A sequência para a determinação da relação a/c pode ser melhor visualizada por meio da Figura 2. 


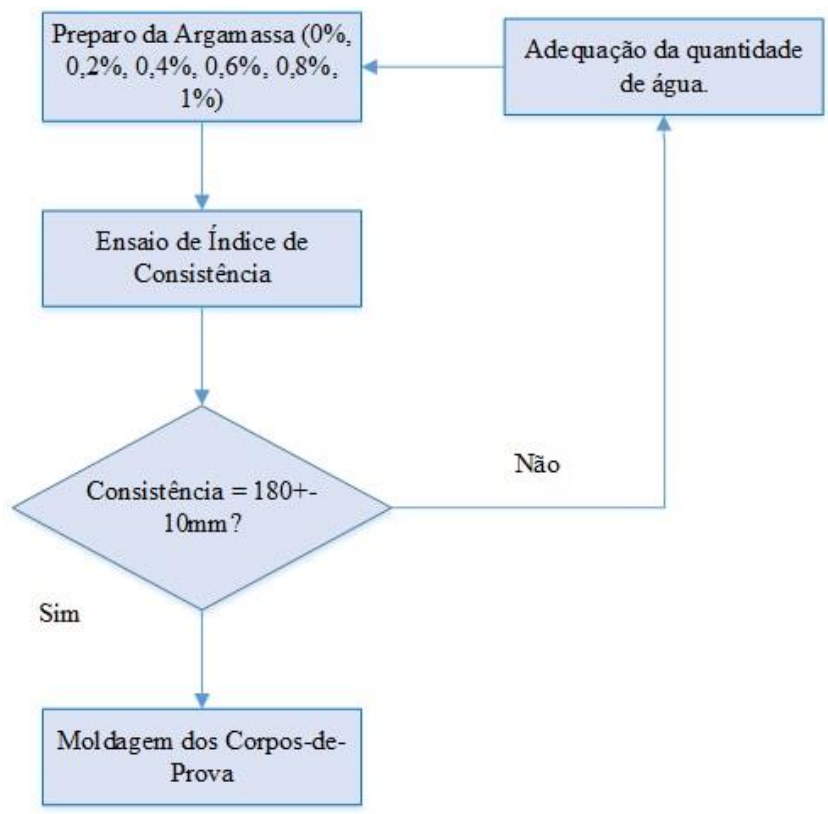

Figura 2: Sequência de preparação da argamassa, ensaio de índice de consistência e determinação da relação a/c.

Conforme pode-se constatar por meio do fluxograma apresentado na Figura 2, primeiramente foi realizada a preparação do traço de argamassa com e sem MCC e, na sequência ocorria o ensaio de índice de consistência e, caso o índice de consistência da argamassa confeccionada fosse igual a $180 \pm 10 \mathrm{~mm}$ passavase para a confecção dos corpos-de-prova, caso contrário a argamassa era rejeitada e retornava-se a etapa de preparo da argamassa para o ajuste na quantidade de água.

Para a preparação das argamassas foram considerados os procedimentos da ABNT NBR 7215 [10]. Para a determinação do índice de consistência das argamassas foram realizados os procedimentos de ensaio definidos pela ABNT NBR 13276 [13]. Após a definição da quantidade de água suficiente para manter o índice de consistência das argamassas fixo em $180 \pm 10 \mathrm{~mm}$, realizava-se a etapa de moldagem dos CP's de argamassa com e sem MCC, para serem submetidos aos ensaios no estado endurecido.

Para a obtenção dos corpos-de-prova cilíndricos, destinados aos ensaios de resistência à compressão e absorção, foram utilizados moldes de aço, com diâmetro interno de $50 \pm 0,2 \mathrm{~mm}$ e altura de $100 \pm 0,5 \mathrm{~mm}$, seguindo os procedimentos estabelecidos pela ABNT NBR 7215 [10]. Já para a obtenção dos corpos-deprova prismáticos, destinados ao ensaio de resistência à tração na flexão, foram utilizados moldes de aço, com $40 \pm 0,4 \mathrm{~mm}$ de profundidade, $40 \pm 0,4 \mathrm{~mm}$ de largura e $160 \pm 0,8 \mathrm{~mm}$ de comprimento, obedecendo aos procedimentos estabelecidos pela ABNT NBR 13279 [14].

\subsection{Ensaios com as argamassas em estado endurecido}

Foram realizados ensaios a fim de se determinar algumas propriedades das argamassas com diferentes teores de MCC, no estado endurecido, sendo que as propriedades avaliadas foram a resistência à compressão, resistência à tração na flexão e absorção de água.

O ensaio de resistência à compressão foi realizado nas idades de 3, 7, 28 e 56 dias, em 3 amostras por idade, para cada uma das taxas de $0 \%, 0,2 \%, 0,4 \%, 0,6 \%, 0,8 \%$ e $1 \%$ de $\mathrm{MCC}$, em relação à massa de cimento. Os corpos-de-prova foram comprimidos axialmente até a sua ruptura, conforme os procedimentos de ensaio definidos pela ABNT NBR 7215 [10].

A resistência à tração na flexão das argamassas foi avaliada em diferentes teores de MCC $(0 \%, 0,2 \%, 0,4 \%$, $0,6 \%, 0,8 \%$ e $1 \%$ ). Essa avaliação se deu por meio do ensaio de corpos-de-prova prismáticos, com 28 dias de idade, em 3 amostras para cada teor de MCC, sendo que estes foram rompidos à flexão, seguindo os procedimentos de ensaio definidos pela ABNT NBR 13279 [14].

A avaliação da absorção de água pelas argamassas foi realizada em corpos-de-prova cilíndricos, com 28 dias de idade, em 3 amostras por traço, de acordo com os procedimentos de ensaio definidos pela ABNT NBR 9778 [15]. 


\subsection{Microscopia eletrônica de varredura}

Para a caracterização morfológica das argamassas com e sem MCC foram coletadas amostras dos corpos-deprova sem adição de MCC e amostras da argamassa com 1\% de MCC, após o seu período de cura. Assim, estas amostras foram levadas à estufa onde permaneceram pelo período de 24 horas, a uma temperatura de $40^{\circ} \mathrm{C}$, para que as mesmas apresentassem menor umidade no momento do ensaio. A fim de se obter as características morfológicas das argamassas com e sem MCC, foi utilizado o microscópio Shimadzu SuperScan SS-550. As amostras foram metalizadas e foram registradas imagens com várias ampliações fotográficas. Este estudo é de caráter unicamente qualitativo, desta forma a microscopia eletrônica de varredura foi realizada com o intuito de visualizar a forma como a MCC se encontra disposta na matriz cimentícia.

\section{RESULTADOS E DISCUSSÃO}

\subsection{Determinação da relação a/c por meio da fixação do índice de consistência}

Primeiramente, utilizou-se a relação a/c recomendada pela ABNT NBR 7215 [10], que é de 0,48 (300 ml de água), para todos os traços de argamassa estudados, ou seja, o traço de argamassa de referência (sem adição de MCC) e os traços de argamassa com adição de $0,2 \%, 0,4 \%, 0,6 \%, 0,8 \%$ e $1 \%$ de MCC, em relação à massa de cimento. A relação a/c em questão foi utilizada no preparo de todos os traços e, na sequência os mesmos passavam pelo ensaio de determinação do índice de consistência, cujos resultados podem ser visualizados na Figura 3.

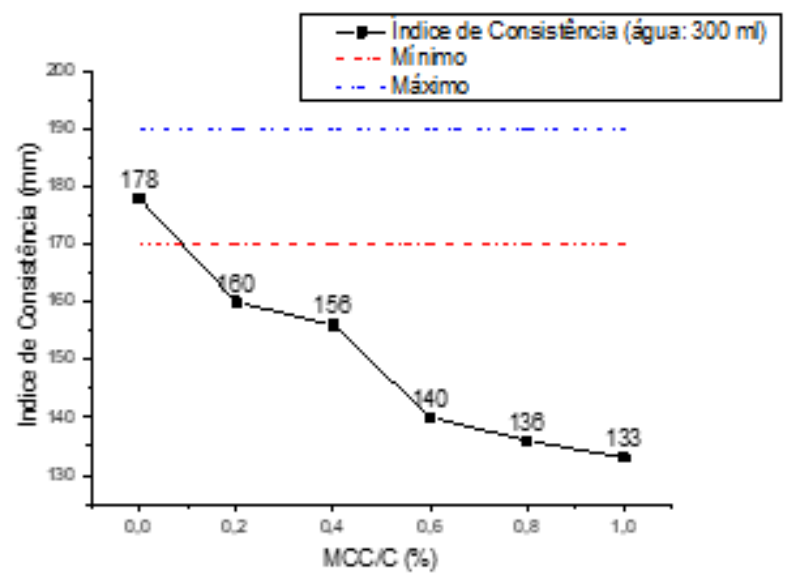

Figura 3: Índice de consistência das argamassas com $300 \mathrm{ml}$ de água (Relação a/c: 0,48).

Conforme pode-se constatar por meio da Figura 3, apenas a argamassa de referência atendeu ao requisito de apresentar índice de consistência igual a $180 \pm 10 \mathrm{~mm}$. Assim sendo, a quantidade de água para a argamassa de referência foi fixada em $300 \mathrm{ml}$, com relação a/c igual a 0,48. Já as argamassas com adição de MCC não atenderam ao requisito de consistência, apresentando uma queda progressiva no índice de consistência à medida em que se aumentava o teor de MCC.

A consistência, um dos fatores que afetam a trabalhabilidade, segundo NEVILLE [16], relaciona-se com a firmeza da forma de uma substância ou com a facilidade com a qual ela flui. Com relação ao concreto, em alguns casos, adota-se a consistência para revelar a quantidade de água na mistura, isto porque, respeitando certos limites, os concretos mais úmidos são mais trabalháveis do que os concretos mais secos.

Os resultados de índice de consistência, obtidos a partir da adição de $300 \mathrm{ml}$ de água, confirmaram a necessidade de se testar novas dosagens deste componente nas argamassas com adição de MCC, com o objetivo de atingir o índice de consistência de $180 \pm 10 \mathrm{~mm}$. No total foram avaliadas 6 variações na relação a/c, sendo que no primeiro teste foram utilizados $300 \mathrm{ml}$ de água (relação a/c de 0,48), conforme já citado. Já no segundo teste, aumentou-se a quantidade de água em 3,3\% $(10 \mathrm{ml})$, isto é, foram utilizados $310 \mathrm{ml}$ para a realização dos traços, ou seja, uma relação a/c de 0,50. A partir do terceiro teste, a quantidade de água acrescida foi de $5 \mathrm{ml}$ em relação a última quantidade testada, ou seja, $315 \mathrm{ml}, 320 \mathrm{ml}, 325 \mathrm{ml}$ e $330 \mathrm{ml}$ que correspondem a $0,50,0,51,0,52$ e 0,53 de relação a/c e aumento, em relação a quantidade de água determinada pela norma, de $5 \%, 6,7 \%, 8,3 \%$ e $10 \%$, respectivamente. À medida em que uma dosagem atendia ao requisito de índice de consistência, a quantidade de água era registrada e adotada para a reprodução dos próximos traços e 
moldagem de CP's.

A Figura 4 ilustra a comparação entre o teor de MCC e a quantidade de água, determinada a partir dos ensaios, necessária para manter o índice de consistência dentro dos padrões fixados inicialmente.

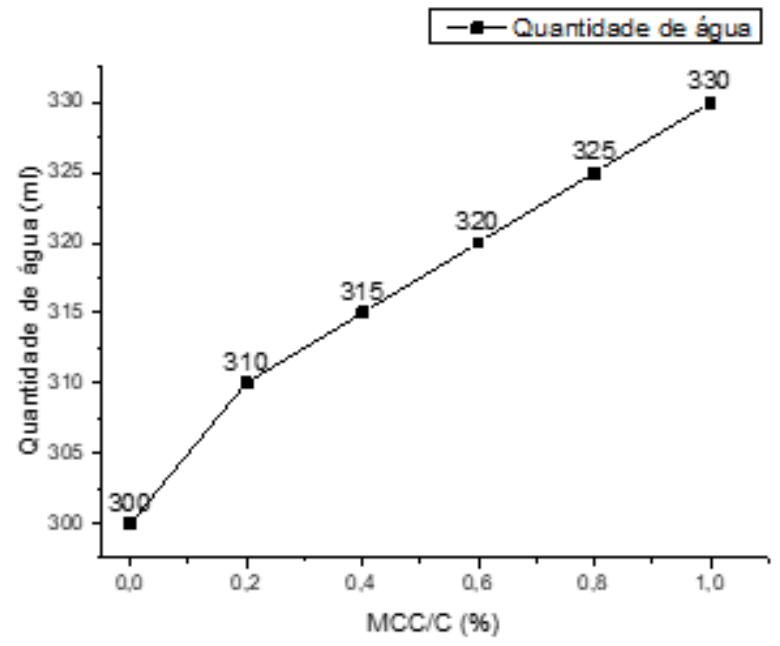

Figura 4: Quantidade de água necessária para manter o índice de consistência em $180 \pm 10 \mathrm{~mm}$.

Os resultados apresentados na Figura 4 mostram que para a argamassa com 0,2\% de MCC atingir um índice de consistência aceitável, foi necessário acrescer $10 \mathrm{ml}$ (aumento de 3,3\%) na quantidade de água definida pela norma seguida na preparação do traço. Na sequência, foi necessário acrescer progressivamente 5 $\mathrm{ml}$ de água aos $310 \mathrm{ml}$ utilizados anteriormente, isto é, $315 \mathrm{ml}, 320 \mathrm{ml}, 325 \mathrm{ml}$ e $330 \mathrm{ml}(5 \%, 6,7 \%, 8,3 \%$ e $10 \%$ de aumento na quantidade de água especificada pela norma), sendo que cada uma destas quantidades atendeu ao requisito de índice de consistência para as argamassas com $0,4 \%, 0,6 \%, 0,8 \%$ e $1 \%$ de MCC, em relação a massa de cimento, respectivamente.

A redução progressiva no índice de consistência das argamassas, a medida em que se aumenta o teor de MCC ocorre, pois, conforme afirma MOHAMMED et al. [17], a MCC possui em sua estrutura molecular a predominância de vários grupos hidroxílicos que atribuem ao material celulósico o comportamento de absorção, ou seja, a MCC acaba absorvendo a água do meio em que está inserida, conforme observado nos ensaios. Isto é, a MCC apresenta a particularidade de absorver a água utilizada na dosagem do compósito cimentício. Esta diminuição no índice de consistência das argamassas condiciona a perda de trabalhabilidade do material, propriedade muito importante no período em que o concreto se encontra no estado fresco. O que acaba por justificar a necessidade em se aumentar a relação a/c nas argamassas, à medida em que se aumenta o teor de MCC, devolvendo-lhe suas características de consistência, anulando assim os efeitos falta de trabalhabilidade no material cimentício.

\subsection{Ensaios com as argamassas em estado endurecido}

\subsubsection{Resistência à compressão}

$\mathrm{O}$ ensaio de resistência à compressão foi realizado em argamassas com idades de 3, 7, 28 e 56 dias, em 3 amostras por idade, para cada uma das taxas de $0 \%, 0,2 \%, 0,4 \%, 0,6 \%, 0,8 \%$ e $1 \%$ de MCC, em relação a massa de cimento, e com índice de consistência fixo em $180 \mathrm{~mm}$. Os resultados deste ensaio apresentam-se na Tabela 2. 
Tabela 2: Resultados do ensaio de resistência à compressão.

\begin{tabular}{|c|c|c|c|c|}
\hline IDADE & MCC/C (\%) & RESISTÊNCIA MÉDIA (MPa) & DESVIO PADRÃO (MPa) & COEFICIENTE DE VARIAÇÃO (\%) \\
\hline \multirow{6}{*}{3 dias } & 0 & 25,6 & 0,59 & $2,31 \%$ \\
\hline & 0,2 & 26,5 & 0,20 & $0,77 \%$ \\
\hline & 0,4 & 24,6 & 0,29 & $1,17 \%$ \\
\hline & 0,6 & 23,8 & 0,53 & $2,21 \%$ \\
\hline & 0,8 & 22,7 & 0,57 & $2,53 \%$ \\
\hline & 1 & 21,5 & 0,47 & $2,17 \%$ \\
\hline \multirow{6}{*}{7 dias } & 0 & 29,1 & 1,03 & $3,53 \%$ \\
\hline & 0,2 & 31,7 & 0,87 & $2,75 \%$ \\
\hline & 0,4 & 28,9 & 0,43 & $1,47 \%$ \\
\hline & 0,6 & 27,9 & 0,38 & $1,38 \%$ \\
\hline & 0,8 & 26,6 & 0,97 & $3,66 \%$ \\
\hline & 1 & 26,3 & 0,95 & $3,60 \%$ \\
\hline \multirow{6}{*}{28 dias } & 0 & 34,2 & 1,36 & $3,99 \%$ \\
\hline & 0,2 & 34,8 & 0,53 & $1,53 \%$ \\
\hline & 0,4 & 29,6 & 0,25 & $0,85 \%$ \\
\hline & 0,6 & 29,4 & 0,53 & $1,79 \%$ \\
\hline & 0,8 & 29,0 & 0,68 & $2,34 \%$ \\
\hline & 1 & 28,6 & 0,80 & $2,78 \%$ \\
\hline \multirow{6}{*}{56 dias } & 0 & 38,4 & 0,27 & $0,70 \%$ \\
\hline & 0,2 & 39,2 & 0,49 & $1,24 \%$ \\
\hline & 0,4 & 37,1 & 0,76 & $2,04 \%$ \\
\hline & 0,6 & 35,3 & 0,72 & $2,03 \%$ \\
\hline & 0,8 & 30,4 & 0,65 & $2,13 \%$ \\
\hline & 1 & 28,9 & 0,71 & $2,48 \%$ \\
\hline
\end{tabular}

Por meio da Figura 5, os resultados referentes à resistência à compressão das argamassas com e sem MCC podem ser melhor visualizados.

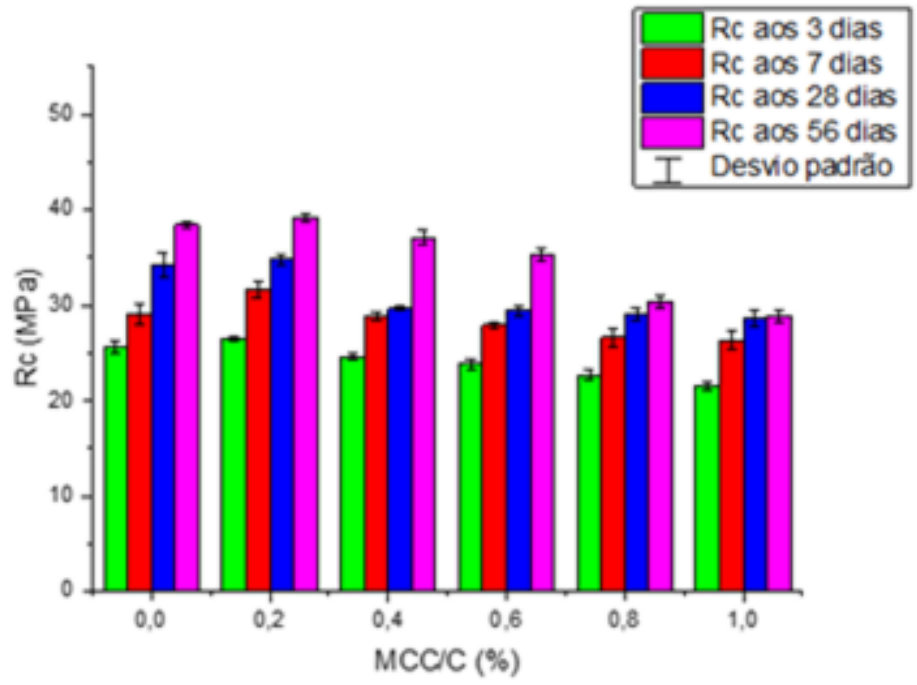

Figura 5: Resistência à compressão das argamassas de referência e com os diferentes teores de MCC.

De acordo com os resultados apresentados, pode-se notar que, em todas as idades, as argamassas com 
adição de $0,2 \%$ de $\mathrm{MCC}$, em relação à massa de cimento, apresentaram maior resistência à compressão quando comparados seus resultados aos das argamassas de referência e argamassas com adição dos demais teores de MCC. Aos 3 dias de idade, a argamassa com adição de 0,2\% de MCC, em relação à massa de cimento, apresentou um acréscimo de $4 \%$ em sua resistência à compressão, quando comparada à argamassa sem adição de MCC, enquanto que as argamassas com os demais teores de MCC apresentaram uma diminuição progressiva na resistência à compressão.

Aos 7 dias de idade as argamassas apresentaram um ganho de resistência à compressão, em relação às argamassas com 3 dias de idade. Outro comportamento que pode ser observado é o de que novamente a argamassa com adição de $0,2 \%$ de $\mathrm{MCC}$, em relação à massa de cimento, apresentou um acréscimo $(9 \%)$ em sua resistência à compressão, quando comparada à argamassa sem adição de MCC. Os demais teores apresentaram queda em seus valores de resistência à compressão.

As argamassas com 28 dias de idade apresentaram um ganho de resistência em relação às idades anteriores, e de maneira semelhante ao ocorrido anteriormente (3 e 7 dias), a argamassa com adição de $0,2 \%$ de MCC, em relação à massa de cimento, apresentou um ganho de $2 \%$ na resistência à compressão quando comparada à argamassa de referência. E também, como vinha acontecendo nas idades anteriores, as argamassas com adição de $0,4 \%, 0,6 \%, 0,8 \%$ e $1 \%$ de MCC apresentaram queda em suas resistências à compressão, de maneira progressiva.

Aos 56 dias houve um aumento nas resistências à compressão das argamassas, em relação aos resultados apresentados aos 28 dias. Observa-se também um aumento de $2 \%$ na resistência à compressão na argamassa com adição de $0,2 \%$, em relação à massa de cimento, quando comparados seus resultados com os da argamassa de referência. E também se verifica que, com exceção do teor de $0,2 \%$ de MCC, à medida em que se aumenta o teor de MCC nas argamassas, a resistência à compressão diminuiu.

Os resultados de resistência à compressão nas argamassas estudadas seguiram um padrão, em que conforme a idade das argamassas aumenta as resistências também apresentam um aumento. Conforme pode ser visualizado na Figura 5, em todas as idades, as argamassas com adição de 0,2\% de MCC, em relação à massa de cimento, apresentaram um leve aumento na resistência à compressão ao serem comparadas às argamassas sem adição de MCC.

Analisando isoladamente a propriedade Resistência à Compressão, levando em consideração as condições em que este estudo foi realizado e os resultados obtidos, pode-se afirmar que a dosagem ótima de MCC a ser adicionada a matriz cimentícia é de $0,2 \%$, em relação à massa de cimento, pois foi a que atribuiu ao material os melhores resultados de resistência à compressão, superando os resultados dos demais teores e até mesmo da argamassa de referência.

As argamassas com as demais adições de $\operatorname{MCC}(0,4 \%, 0,6 \%, 0,8 \%$ e $1 \%)$ apresentaram um declínio em sua resistência. De acordo com ANJU et al. [18], durante o processo de mistura da argamassa, a MCC é o componente mais hidrófilo por natureza, absorvendo mais água e, consequentemente, a quantidade de água disponível não é suficiente, nas fases iniciais, para realizar a ligação cruzada do crescimento de CSH, o que pode resultar em uma menor resistência à compressão do composto cimentício.

Além disso, deve-se verificar a eficiência do método de dispersão da MCC empregado, pois à medida em que se aumenta o teor de MCC adicionado às argamassas é possível que ocorra sua aglomeração, quando não há uma dispersão uniforme da mesma na matriz cimentícia a ação dos microcristais como reforço pode ser comprometida, resultando na perda de resistência.

CAO et al. [4] também atingiu seu maior resultado de resistência à compressão nas pastas de cimento com adição de um teor $0,2 \%$, no entanto o material estudado pelos autores foi a NCC, alcançando um aumento de $30 \%$ na resistência, o que se justifica pelo fato de as partículas utilizadas pelos autores se apresentarem na nanoescala, possibilitando sua ação na nano e microestrutura do material cimentício.

SILVA [5], realizou um estudo de argamassas com a mesma MCC e com os mesmos teores de MCC analisados neste estudo, no entanto, manteve fixa a dosagem de água utilizada nos traços com os diferentes teores de MCC em $300 \mathrm{ml}$. De acordo com seus resultados a adição de 0,2\% de MCC, em relação à massa de cimento, também apresentou aumento na resistência à compressão em todas as idades. $\mathrm{O}$ autor expõe que o maior ganho de resistência à compressão se deu nas idades de 7 e de 28 dias, com aumento de cerca de $30 \%$ em relação à argamassa de referência. $\mathrm{O}$ autor destaca que as adições de $0,4 \%, 0,6 \%, 0,8 \%$ e $1 \%$, no geral, não proporcionam aumento de resistência, no entanto não prejudicam as propriedades mecânicas dos compósitos.

Ao analisar os resultados alcançados por SILVA [5], nota-se que os valores das resistências alcançados em sua pesquisa são de uma ordem bem maior que os resultados apresentados no presente estudo. No 
entanto, cabe salientar que tais diferenças nos resultados se dão graças a fixação no índice de consistência, em $180 \pm 10 \mathrm{~mm}$, realizado no presente estudo. Conforme visto anteriormente, para que o índice de consistência pudesse se manter fixo, foi necessário aumentar a quantidade de água, de maneira progressiva, à medida em que se majorava o teor de MCC nas argamassas. É necessário compreender que, o aumento na relação a/c em matrizes cimentícias implica na perda de resistência, no entanto este estudo propõe a análise das propriedades das argamassas a partir da variação de dois elementos, a relação a/c e a MCC. De maneira que seria incorreto analisar a resistência à compressão apenas a partir da variação de MCC.

No estudo realizado por SILVA [5], o valor fixado foi o da relação a/c, aceitando-se e registrando-se o índice de consistência resultante desta dosagem. Desta maneira, a análise da resistência à compressão pôde ser levada em conta com a variação de apenas um elemento, a MCC. De acordo com os resultados alcançados pelo autor, ao aumentar as taxas de MCC foi possível alcançar resultados de resistências à compressão maiores do que os resultados alcançados no presente estudo, pois somente era analisada a variação no teor de MCC nas argamassas, de forma que, mantendo a relação a/c constante é natural que a resistência não apresente quedas. Entretanto, manter a relação a/c constante, neste caso, resulta na perda de trabalhabilidade do compósito cimentício com o acréscimo de MCC.

\subsubsection{Resistência à tração na flexão}

Os resultados do ensaio de resistência à tração na flexão obtidos para as argamassas, aos 28 dias de idade, apresentam-se na Tabela 3.

Tabela 3: Resultados do ensaio de resistência à tração na flexão.

\begin{tabular}{l|l|l|l|l}
\hline IDADE & MCC/C (\%) & RESISTÊNCIA MÉDIA (MPa) & DESVIO PADRÃO (MPa) & COEFICIENTE DE VARIAÇÃO (\%) \\
\hline \multirow{4}{*}{28 dias } & 0 & 6,7 & 0,09 & $1,40 \%$ \\
\cline { 2 - 5 } & 0,2 & 7,1 & 0,17 & $2,38 \%$ \\
\cline { 2 - 5 } & 0,4 & 6,1 & 0,13 & $2,10 \%$ \\
\cline { 2 - 5 } & 0,6 & 5,5 & 0,07 & $1,31 \%$ \\
\cline { 2 - 5 } & 0,8 & 5,4 & 0,05 & $0,91 \%$ \\
\cline { 2 - 5 } & 1 & 5,2 & 0,16 & $3,15 \%$ \\
\hline
\end{tabular}

O comportamento das argamassas nos ensaios de resistência à tração na flexão se apresentou de maneira semelhante ao comportamento constatado nos ensaios de resistência à compressão, conforme pode ser verificado na Tabela 3 , há um acréscimo na resistência à tração nos corpos-de-prova com adição de $0,2 \%$ de MCC, em relação à massa de cimento. Este acréscimo na resistência é de $6 \%$ em relação à argamassa de referência. Quando comparadas à argamassa de referência, as argamassas com adição de 0,4\%, 0,6\%, 0,8\%, $1 \%$ de MCC apresentaram queda nos resultados de resistência à tração na flexão, conforme pode ser observado na Figura 6.

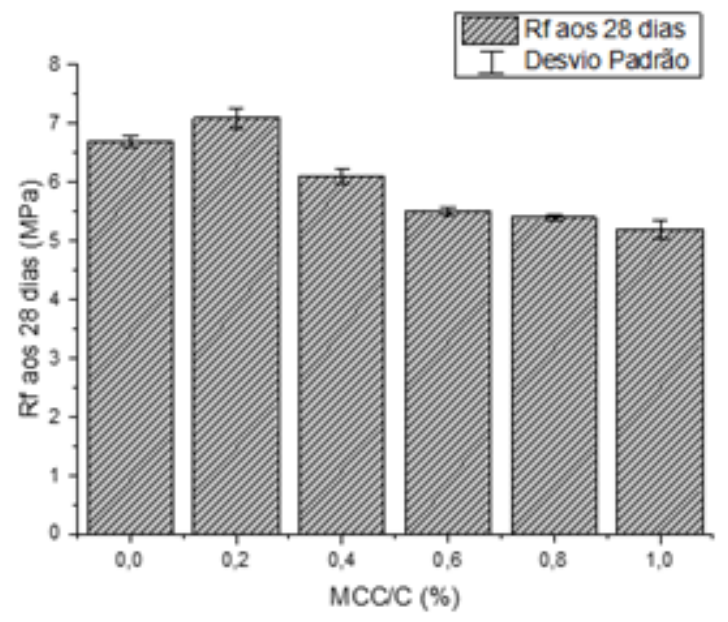

Figura 6: Resistência à tração na flexão das argamassas de referência e com os diferentes teores de MCC. 
Por meio da Figura 6 pode-se verificar o comportamento dos resultados de resistência à tração na flexão nas argamassas. Analisando isoladamente a propriedade resistência à tração na flexão, considerando as condições em que este ensaio foi realizado, pode-se concluir que a quantidade ótima de MCC a ser adicionada à argamassa é de $0,2 \%$, pois foi a que proporcionou à argamassa os melhores resultados de resistência à tração na flexão, superando os resultados registrados para a argamassa de referência, bem como dos demais teores de MCC.

SILVA [5] também analisou o efeito das mesmas proporções de MCC na resistência à tração na flexão de argamassas cimentícias. Seus resultados demonstraram um aumento progressivo na resistência à tração na flexão, partindo da argamassa de referência até a adição de 0,6\% de MCC, que foi onde se registrou o pico máximo de resistência, de 7,67 $\mathrm{MPa}$, resultado $20 \%$ maior do que a resistência apresentada pela argamassa de referência. A partir da adição de $0,8 \%$ de MCC verificou-se que a resistência começou a cair, no entanto, as argamassas com $0,8 \%$ e $1 \%$ ainda apresentaram resistências mais elevadas que a argamassa de referência.

Estes valores foram obtidos pois, o autor conseguiu proporcionar ao material cimentício uma maior concentração da microfibra como reforço, mantendo a relação a/c constante. No presente estudo, ao se adicionar $0,6 \%$ de MCC às argamassas, foi necessário aumentar em $6,7 \%$ a quantidade de água para não prejudicar a trabalhabilidade do material, o que fez com que a resistência à tração na flexão apresentasse uma queda, quando comparada com a argamassa de referência. Todavia, ao acrescentar 0,2\% de MCC às argamassas, mesmo sendo necessário aumentar a quantidade de água em 3,3\%, a resistência à tração apresentou um aumento de 6\%, em relação à argamassa de referência.

Além do aumento na relação a/c ser um dos possíveis causadores na queda da resistência, nas adições $0,4 \%, 0,6 \%, 0,8 \%$ e $1 \%$, também deve ser levada em conta a possibilidade de a MCC não estar totalmente dispersa nas argamassas, o que acaba causando prejuízos nos resultados das resistências. De acordo com PARVEEN et al. [6] assim como em outros materiais nano e micro, a dispersão da MCC é altamente importante, no que se diz respeito às propriedades mecânicas, tendo em vista que a aglomeração de MCC pode reduzir significativamente a sua eficiência de reforço e provocar defeitos nos materiais cimentícios.

\subsubsection{Absorção de água nas argamassas}

Após o registro dos dados referentes à massa das amostras secas, massa das amostras imersas e massa das amostras saturadas, foi possível calcular a absorção de água nas argamassas, com e sem MCC. A Figura 7 apresenta o resultado e comportamento da absorção de água nas argamassas, à medida em que se aumenta o teor de MCC.

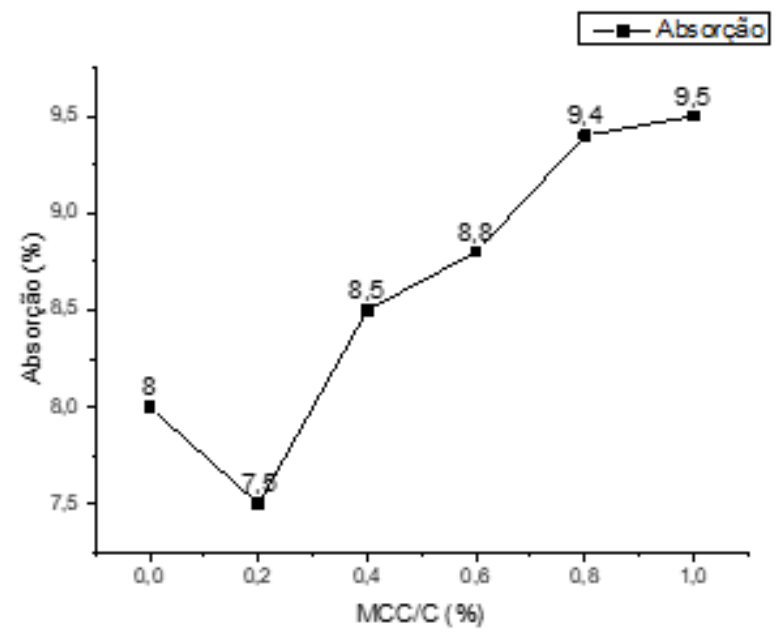

Figura 7: Absorção de água nas argamassas de referência e com os diferentes teores de MCC.

Analisando comportamento apresentado na Figura 7, pode-se constatar que a absorção de água nas argamassas com adição $0,2 \%$ de MCC, em relação à massa de cimento, foi menor do que a absorção registrada para as argamassas sem adição de MCC. Nota-se também, que a partir da adição de $0,4 \%$ MCC até a adição de $1 \%$ de MCC, em relação à massa de cimento, a absorção de água apresentou um aumento crescente, quando comparada aos resultados registrados para a argamassa sem adição de MCC. Este aumento na absorção de água pode se dar devido ao fato de a MCC apresentar um comportamento hidrofílico, desta forma, quando 
presente na matriz cimentícia em maiores concentrações, a MCC acrescenta ao material a característica de retenção de água.

Os índices de vazios das argamassas foram determinados e seus resultados podem ser observado na Figura 8.

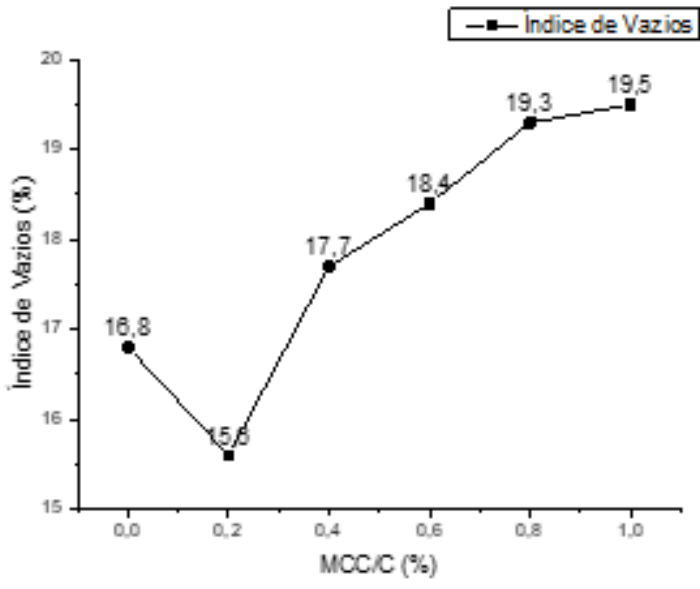

Figura 8: Índice de vazios das argamassas de referência e com os diferentes teores de MCC.

Constata-se por meio dos resultados apresentados Figura 8, que, de forma semelhante ao ocorrido com os resultados de absorção de água, o índice de vazios da argamassa com adição de $0,2 \%$ de MCC foi menor do que o índice de vazios da argamassa de referência, o que acaba justificando a menor absorção de água obtida para as argamassas com adição de $0,2 \%$ de MCC. A partir da adição de $0,4 \%$ MCC até a adição de $1 \%$ de MCC, em relação à massa de cimento, o índice de vazios também apresentou um aumento progressivo, quando comparado ao resultado registrado para a argamassa de referência.

A Figura 9 apresenta a comparação entre o comportamento da absorção e índice de vazios e o comportamento de resistência à compressão nas argamassas, aos 28 dias de idade.

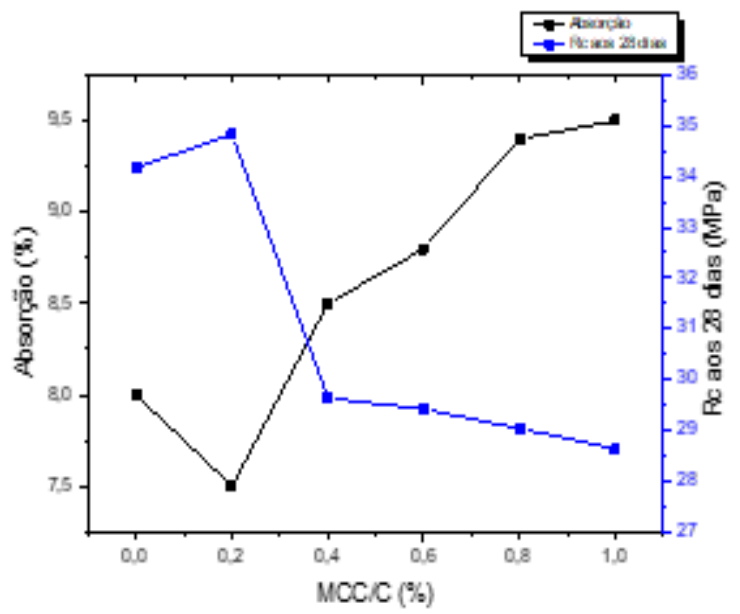

(a)

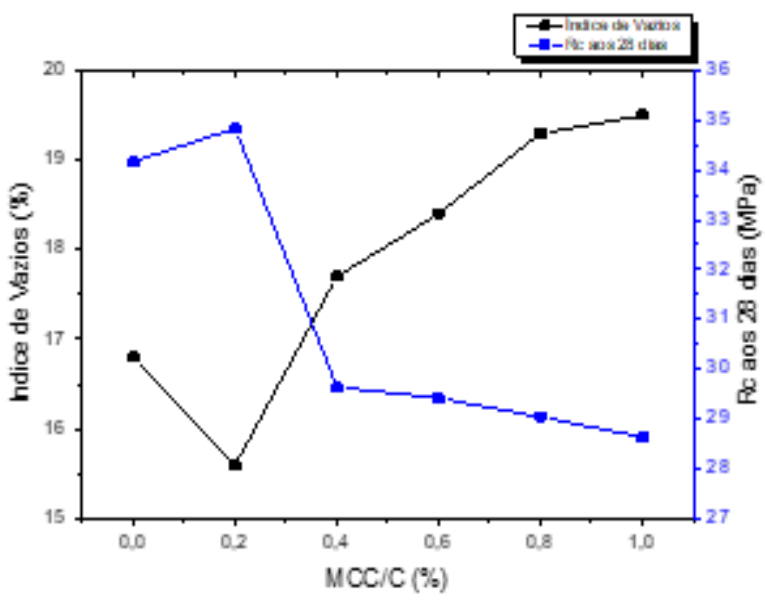

(b)

Figura 9: Comparação: (a) absorção $\mathrm{X}$ resistência à compressão aos 28 dias e (b) índice de vazios X resistência à compressão aos 28 dias.

Assim como um maior índice de vazios pode proporcionar uma maior absorção de água nas argamassas, é natural que as argamassas que apresentem menor índice de vazios e absorção apresentarão, por consequência, maiores resistências, da mesma maneira que índice de vazios e absorção maiores apresentarão resistências menores. Conforme pode ser observado na Figura 9, o comportamento de absorção e índice de vazios são inversamente proporcionais ao comportamento da resistência. 
A redução na necessidade de absorver água proporcionada pela adição de $0,2 \%$ de MCC nas argamassas, denota a aptidão de tal dosagem de MCC para aumentar a durabilidade do material cimentício. Desta forma, analisando a propriedade absorção de água, e levando em consideração as condições em que este ensaio foi realizado, pode-se afirmar que o teor ótimo de MCC a ser adicionado à argamassa é de $0,2 \%$, pois diminui a capacidade de absorção de água nas argamassas, quando comparado à argamassa com os demais teores de MCC e com a argamassa de referência.

\subsection{Microscopia eletrônica de varredura (MEV)}

Foram registradas imagens, pelo MEV, em diferentes ampliações em argamassas com 1\% de MCC, em relação à massa de cimento, e em argamassas sem a adição de MCC. A Figura 10 apresenta a captura de imagens, nas ampliações de 300x e 100x.

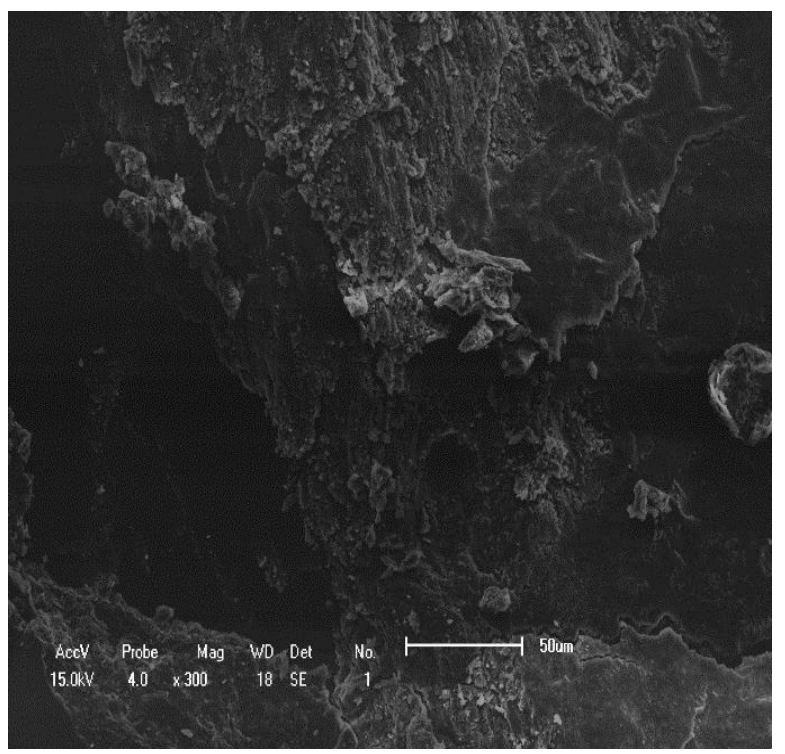

(a)

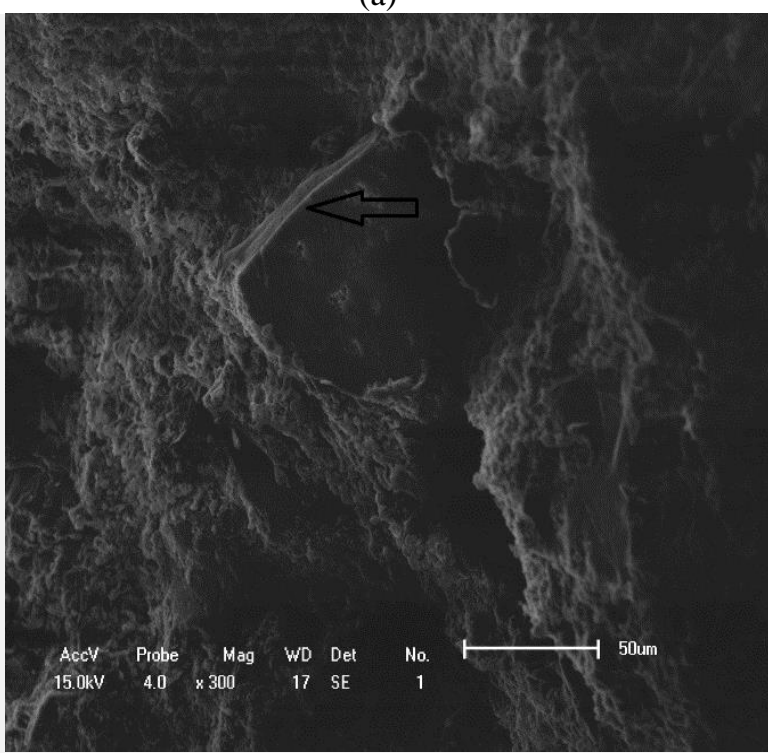

(c)

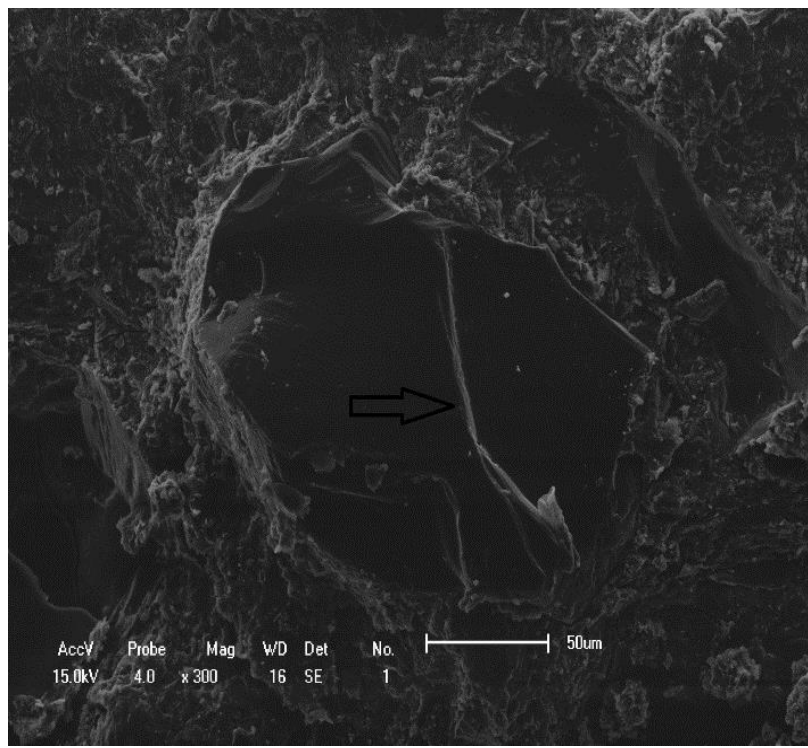

(b)

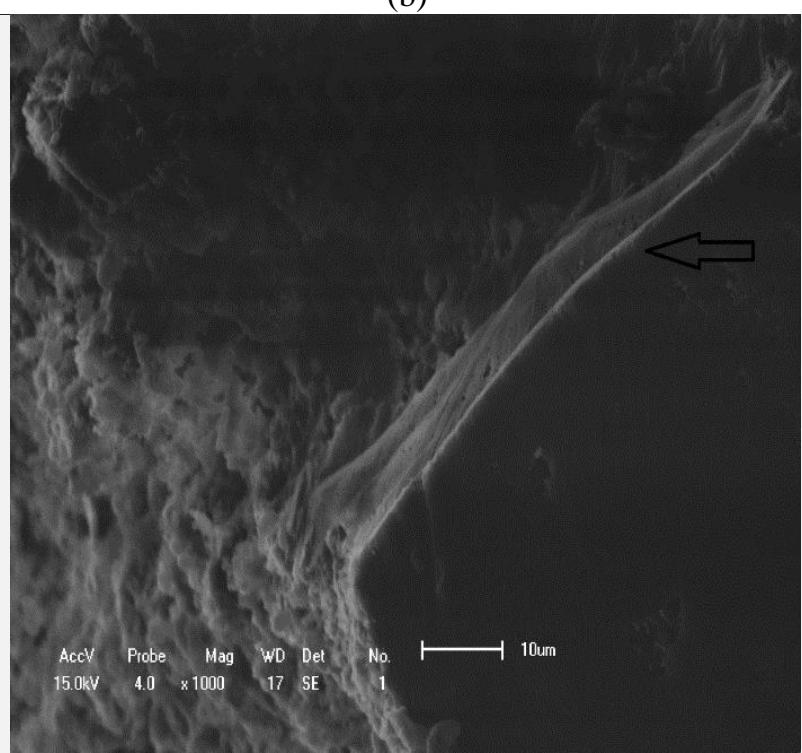

(d)

Figura 10: Microscopia eletrônica de varredura das amostras: (a) microestrutura da argamassa sem adição de MCC; (b); (c); (d) microestruturas da argamassa com adição de $1 \%$ de MCC.

Para a captura de imagens da amostra da Figura 10a, foi utilizado um fragmento do corpo-de-prova utilizado no ensaio de resistência à compressão aos 28 dias, sem adição de MCC. A amostra b, foi retirada do corpo-de-prova utilizado no ensaio de resistência à compressão aos 28 dias, com adição de $1 \%$ de MCC, em 
relação à massa de cimento. Já as imagens registradas na amostra $\mathrm{c}$ e d, foram realizadas em fragmento retirado do corpo-de-prova utilizado no ensaio de absorção, aos 28 dias, com adição de $1 \%$ de MCC, em relação à massa de cimento.

Faz-se importante ressaltar que a captura de imagens por meio do MEV consiste em uma prática puramente qualitativa, não fornecendo base para conclusões a respeito da atuação da MCC no interior das argamassas, no entanto sua análise permite a constatação de sua disposição no interior do material cimentício acompanhada de algumas considerações.

Não se verificou a degradação da MCC, em nenhuma destas amostras analisadas, quando analisados os microcristais que foram identificados, considerando que as mesmas passaram pelo processo de cura, no caso do fragmento retirado do ensaio de absorção, este passou por uma secagem em estufa $\left(105^{\circ} \mathrm{C}\right)$, durante 72 horas, e foi submetido à absorção de água por imersão. Pode-se afirmar, por meio das imagens capturadas, que as micropartículas que puderam ser identificadas resistiram aos processos aos quais foram submetidas sem apresentar degradação.

Conforme pode ser visualizado na Figura 10, a MCC se encontra disposta em vazios na matriz cimentícia, e, de acordo com as imagens capturadas não foi constatada a aglomeração das micropartículas, sendo possível identificá-las individualmente. Nesta análise, a MCC só pôde ser identificada quando se encontrava em vazios, pois na ausência destes a mesma tende a ser envolvida pela argamassa. Embora seja um ensaio apenas de caráter qualitativo, foi possível identificar a MCC no interior do material cimentício e verificar a maneira como a mesma se dispõe no interior da matriz, ligando o poro de uma extremidade a outra.

A partir da Figura 10 pode-se constatar a estrutura fibrosa da MCC, tendo em vista sua elevada área superficial e tamanho de partícula, conforme caracterização fornecida pelo fabricante, de $51 \mu \mathrm{m}$. De acordo com GRAEFF [19], pode-se considerar as fibras vegetais como sendo compostos naturais que se constituem principalmente de fibrilas de celulose, estas fibrilas são alinhadas, o que pode resultar em uma elevada resistência à tração e à flexão, proporcionando ainda uma maior rigidez. Assim sendo, as microfibras são capazes de atuar na microestrutura do material cimentício, acrescentando-lhe melhores propriedades mecânicas ao preencher seus vazios, quando incorporadas em pequenas dosagens.

Os resultados de resistência alcançados pelas argamassas com adição de $0,2 \%$ de MCC, em relação à massa de cimento, podem não ser considerados elevados, quando analisados os incrementos obtidos em comparação com as argamassas sem adição de MCC. No entanto, este baixo incremento de resistência pode se dar devido a um método inadequado de dispersão da MCC no interior das argamassas.

\section{CONCLUSÕES}

Este trabalho buscou avaliar a influência da microcelulose cristalina nas propriedades mecânicas de argamassas cimentícias. Para isto, foram avaliados traços de argamassa sem adição de MCC (referência) e com adição de $0,2 \%, 0,4 \%, 0,6 \%, 0,8 \%$ e $1 \%$ e MCC, em relação à massa de cimento. Após a realização do estudo, pode-se chegar as seguintes conclusões:

- Levando em consideração o caráter hidrofílico da MCC, foi necessário encontrar uma relação a/c, para cada teor de MCC adicionado às argamassas. Este ajuste na relação a/c se fez indispensável pois, este estudo teve como uma de suas finalidades desenvolver argamassas com condições ideais de trabalhabilidade, as quais não poderiam ser proporcionadas sem a realização do ajuste;

- Com relação à resistência à compressão das argamassas testadas, pode-se afirmar que a dosagem ótima de MCC, de acordo as condições em que os ensaios foram realizados neste estudo, é de $0,2 \%$, em relação à massa de cimento. Registrando aumentos de $4 \%$ na resistência à compressão aos 3 dias de idade, de $9 \%$ aos 7 dias, $2 \%$ aos 28 dias e $2 \%$ aos 56 dias, quando comparados seus resultados aos da argamassa sem adição de MCC;

- Com a realização do ensaio de resistência à tração na flexão, foi possível constatar que as argamassas com adição de $0,2 \%$ de MCC alcançaram os melhores resultados, registrando um aumento de $6 \%$ na resistência à tração na flexão, aos 28 dias, em comparação com a argamassa de referência.

- Por meio da realização do ensaio de absorção de água, foi possível constatar que as argamassas com adição de 0,2\% de MCC, em relação à massa de cimento, apresentaram os melhores resultados, pois a porcentagem de absorção de água e índice de vazios registrados foram menores que os da argamassa de referência e argamassas com os demais teores de MCC;

- Com a realização da captura de imagens por meio do MEV foi possível identificar a MCC disposta em vazios no interior das argamassas, ligando os mesmos de uma extremidade à outra. Não 
se verificou a aglomeração nem a degradação das micropartículas, levando em conta as que puderam ser identificadas. Não se pode estender a afirmação sobre a não aglomeração e não degradação das micropartículas que não puderam ser identificadas por estarem envolvidas pela argamassa.

Os ganhos de resistência, tanto à compressão como à tração na flexão, são considerados baixos, porém deve-se considerar o avanço em tais resultados levando em conta o aumento na quantidade de água necessário para manter a trabalhabilidade da argamassa. Resultados superiores de resistência poderiam ser alcançados caso se eliminasse a necessidade do aumento da quantidade de água por meio da utilização de aditivo superplastificante, que poderia proporcionar a manutenção da relação a/c, melhoria nas condições de trabalhabilidade do material e ainda, apresentaria o potencial de melhorar sua resistência.

Finalmente, em resposta ao objetivo deste estudo, avalia-se que a influência da adição dos diferentes teores de MCC nas argamassas, com índice de consistência fixo, varia de acordo com a dosagem de MCC. Enquanto os teores de $0,4 \%, 0,6 \%, 0,8 \%$ e $1 \%$ de $\mathrm{MCC}$, em relação à massa de cimento, em combinação com suas respectivas relações a/c, causaram prejuízos às propriedades mecânicas das argamassas, a adição de $0,2 \%$ de MCC, combinada com sua relação a/c, atribuiu ao material melhores propriedades, ou seja, maior resistência à compressão e à tração na flexão e menor absorção de água e menor índice de vazios.

\section{AGRADECIMENTOS}

Ao Laboratório de Materiais de Construção, ao Complexo de Centrais de Apoio à Pesquisa (COMCAP), ao Programa de Pós-Graduação em Engenharia Urbana (PEU) e ao Departamento de Engenharia Civil (DEC), da Universidade Estadual de Maringá (UEM), pela estrutura e equipamentos utilizados durante a pesquisa.

Ao Instituto de Pesquisas Tecnológicas (IPT), pela doação da areia normal utilizada na pesquisa.

\section{BIBLIOGRAFIA}

[1] MEHTA, P. K., MONTEIRO, P. J. M. Concreto: Microestrutura, propriedades e materiais, 2 ed, São Paulo, Ed. Ibracon, 2008.

[2] HOYOS, C., CRISTIA, E., VÁZQUEZ, A. "Effect of cellulose microcrystalline particles on properties of cement based composites", Materials and Design, v. 51, pp. 810-818, Apr. 2013.

[3] DUART M. A. Estudo da microestrutura do concreto com adição de cinza de casca de arroz residual sem beneficiamento, Dissertação de M.Sc., Universidade Federal de Santa Maria, UFSM, Santa Maria, RS, 2008.

[4] CAO, Y., ZAVATERRI , P., YOUNGBLOOD, J., et al. "The influence of cellulose nanocrystal additions on the performance of cement paste", Cement and Concrete Composites, v. 56, p. 73-83, Nov. 2015.

[5] SILVA, L. F. Estudo do efeito da microcelulose sobre o desempenho de materiais compósitos de matriz cimentícia. Dissertação de M.Sc., Universidade Estadual de Maringá, UEM, Maringá, PR, 2016.

[6] PARVEEN, S., RANA, S., FANGUEIRO, R., et al. "A novel approach of developing micro crystalline cellulose reinforced cementitious composites with enhanced microstructure and mechanical performance", Cement and Concrete Composites, v. 78, pp. 146-161, Jan. 2017.

[7] INTERCEMENT, CP V ARI Estrutura -Cauê, http://www.intercement.com/files/pdf/portugues-br/cpvari-estrutura.pdf. Acessado novembro de 2016.

[8] ASSOCIAÇÃO BRASILEIRA DE NORMAS TÉCNICAS. ABNT NBR 5733. Cimento Portland com alta resistência inicial. Rio de Janeiro, 1991.

[9] ASSOCIAÇÃO BRASILEIRA DE NORMAS TÉCNICAS. ABNT NBR 7214. Areia normal para ensaio de cimento. Rio de Janeiro, 2015.

[10] ASSOCIAÇÃO BRASILEIRA DE NORMAS TÉCNICAS. ABNT NBR 7215. Cimento Portland determinação da resistência a compressão. Rio de Janeiro, 1996.

[11] SIGMA ALDRICH, Cellulose microcrystalline, powder, http://www.sigmaaldrich.com/catalog/product/aldrich/435236?lang=pt\&region=BR. Acessado em janeiro de 2016.

[12] PARVEEN, S., RANA, S., FANGUEIRO, R. "A review on nanomaterial dispersion, microstructure, and mechanical properties of carbon nanotube and nano fiber reinforced cementitious composites", Journal of Nanomaterials, v. 2013, p. 1-19, May. 2013. 
[13] ASSOCIAÇÃO BRASILEIRA DE NORMAS TÉCNICAS. ABNT NBR 13276. Argamassa para assentamento e revestimento de paredes e tetos. Preparo da mistura e determinação do índice de consistência. Rio de Janeiro, 2005.

[14] ASSOCIAÇÃO BRASILEIRA DE NORMAS TÉCNICAS. ABNT NBR 13279. Argamassa para assentamento e revestimento de paredes e tetos - Determinação da resistência à tração na flexão e à compressão. Rio de Janeiro, 2005.

[15] ASSOCIAÇÃO BRASILEIRA DE NORMAS TÉCNICAS. ABNT NBR 9778. Argamassa e Concreto endurecidos - Determinação da absorção de água, índice de vazios e massa específica. Rio de Janeiro, 2009.

[16] NEVILLE, A. M. Propriedades do concreto, 6 ed, Porto Alegre, Ed. Bookman LTDA, 2016.

[17] MOHAMMED, M. S., AHMED, A. E. S. I., OSMAN, R. M. "Microcrystalline cellulose as a reinforcement agent to cement pastes", Pigment \& Resin Technology, v. 43, pp.104 - 110, 2014.

[18] ANJU, T. R., RAMAMURTHY, K., DHAMODHARAN, R. "Surface modified microcrystalline cellulose from cotton as a potential mineral admixture in cement mortar composite", Cement and Concrete Composites, v. 74, pp. 147-153, Sep. 2016.

[19] GRAEFF, C. Nanotecnologia, ciência e engenharia, 1 ed, São Paulo, Cultura Acadêmica, 2012. 